\title{
Magnitude of Preterm Birth Admission, Immediate Outcomes and Their Predictors in Debre Markos Referral Hospital, North West, Ethiopia.
}

Birtukan Assefa ( $\sim$ birtukanassefa19@gmail.com )

Debre Markos University https://orcid.org/0000-0001-7264-4743

Abebe Abate

Debre Markos University

Tadesse Yirga

Debre Markos University

\section{Research}

Keywords: Preterm birth, neonatal intensive care unit, immediate outcomes, Ethiopia

Posted Date: July 13th, 2021

DOI: https://doi.org/10.21203/rs.3.rs-676002/v1

License: (c) (i) This work is licensed under a Creative Commons Attribution 4.0 International License. Read Full License 


\section{Abstract}

Background: Each year 15 million preterm babies are born. Pre-term birth complications account for $35 \%$ of the estimated 3.1 million global neonatal deaths and are the second leading cause of death in children less than 5 years aged.

Objective: we assessed the magnitude of preterm birth admissions, immediate outcomes and their predictors in Debre Markos Referral Hospital, North West, Ethiopia, 2019.

Methodology: An institutional based retrospective cross- sectional study design was conducted among 212 neonates registered from January 1, 2014, to January 1, 2019. Data was entered using Epidata version 3.1 and exported to SPSS version 20 for analysis. Bivariable and multivariable logistic regressional analysis were done. Variables with $p$ value $<0.05$ in multivariate analysis were declared as statistically significant at a $95 \%$ confidence interval.

Results: Out of 212 neonates involved in the study, $27.8 \%$ were preterm birth admissions. From this $36.3 \%$ of neonates was died before discharge. In the final multivariate analysis hypertension during pregnancy was significantly associated for preterm admissions $(P=0.013$, AOR $=4.464,95 \% \mathrm{Cl}:(1.375,14.498))$ and being extreme low and very low birth weight $(P=0.005, A O R=2.107,95 \% \mathrm{Cl}:(0.023,0.508))$ and those with low APGAR score $(P=0.016, A O R=3.113,95 \% \mathrm{Cl}(0.019,0.669))$ was significantly associated with death before discharge.

Conclusion: Preterm admissions accounted for a significant percentage of neonatal admissions with significant death outcomes. Maternal medical problems like hypertension during pregnancy, premature rupture of membrane had significant association for preterm admissions. Also, being extreme low weight and very low weight baby, low APGAR score had significant association with death outcome of preterm neonates. Therefor, strategies should be designed to prevent preterm birth and their complications. Special attention should be given for pregnant mothers having medical problems especially hypertension. Furthermore, health institutions should have organised ANC follow up for regular screening of pregnant mothers for medical and obstetric complications.

\section{Introduction}

Now a day's preterm birth is increasing across the globe. Globally, an anticipated 15 million infants are born too early each year. Recent estimates of preterm birth rates (all live births before 37 completed weeks) for 184 countries in 2010 and a time series for 65 countries suggest that 14.9 million (range from: 12.3-18.1 million) babies were born preterm in 2010 (1). More than $60 \%$ of all premature babies are born in South Asia and subSaharan Africa, with just over half now being born in facilities(2, 3). In Ethiopia, 320,000 premature babies are born annually(4)

Complications of preterm birth are the single largest direct cause of neonatal deaths, responsible for $35 \%$ of the world's 3.1 million deaths per year, and the second most common cause of under-5 deaths. Almost $1,000,000$ youngsters die every year because of preterm delivery. In Ethiopia 24,000 less than five children die 
annually due to direct preterm complications (4). In addition to its significant contribution to mortality, the effect of preterm complications among survivors may continue throughout life (5).

Different strategies have been implemented to reduce the neonatal mortality rate across the globe. According to the recent UN estimate, the neonatal mortality reduced by $48 \%$ from the 1990 estimate to 28 per 1000 live births in 2013 while the reduction rate of under-five mortality rate was by about $67 \%$. From this neonatal death preterm birth accounts $37 \%(6)$.

Regardless of significant success in infant and under-5 deaths in Ethiopia, the reduction in neonatal mortality is relatively low. Based on EDHS 2011 report, the Neonatal Mortality Rate was 37/1000 live births, which has not shown significant declines from the 2005 EDHS report of 39/1000 live births(7, 8). A study conducted in Southwest Ethiopia, Jimma zone indicates neonatal mortality rate in 2013 was 35.5 per 1000 live-births. $69.1 \%$ of them died within the first week of life making weighted early neonatal mortality rate to be 23.7 and risk of neonatal death was found to be increased in prematurity as compared to term births(9).

Different reasons contribute for the morbidity and deaths of preterm neonate $(10,11)$. In developing countries particularly in Ethiopia most preterm births occur after 32 weeks of gestation (84\%) and deaths in these babies can almost all be prevented by essential new-born care $(2,3)$. In low earning areas, $1 / 2$ of the infants born under 32 weeks die because of a loss of feasible and cost-powerful care including warmth, breastfeeding aid, simple take care of infections and helping baby to breathe (1).

Studies indicate that, prematurity, low birth weight for gestational age; male sex, maternal hypertension during pregnancy, Home delivery, cry immediately at birth, hypoglycaemia at admission, presence of jaundice, hyaline membrane disease was significantly associated with neonatal mortality.

\section{Methods}

\section{Study setting}

The study was carried out at the Neonatal Intensive Care Unit (NICU) of the Debre Markos compressive specialized referral Hospital. Debremarkos is a capital city of East Gojjam Zone Amhara Regional State 299 $\mathrm{Km}$ from Addis Ababa. Debre Markos compressive specialized hospital is the only referral hospital found in the zone and serves for more than five million people.

\section{Study Design}

A five years institutional based retrospective cross- sectional study design was conducted.

\section{Study Population}

All neonates admitted in NICU from January 1, 2014, to January 1, 2019 with complete medical record were included in the study.

\section{Sample Size Determination and Sampling procedure}


The total sample size 228 was determined using the assumption of a single population proportion formula by taking P-value from the previous study $16 \%, 95 \%$ confidence interval $(\mathrm{Cl}), 80 \%$ power, $5 \%$ margin of error $(d=0.05)$ and $10 \%$ incomplete data. The required sample size was selected by first, assessing the total neonates admitted in the NICU in the database on the registered chart/form from the discharge catalog of admitted patient's in neonatal intensive care unit from January 1,2014 , to January 1,2019 . Then the medical registration numbers of all admitted neonatal patients were sorted. After this, a systematic random technique was applied to select the required sample size.

\section{Data collection tool and methods}

A check list adapted from different literatures was used to collect the data. The checklist measures the sociodemographic, maternal related factors, neonatal related factors. Pretest was done on $5 \%$ of neonatal charts and necessary corrections were made on the check list. Four trained BSc nurses working in the NICU and one MSc nurse supervisors were collected the data.

\section{Data Processing and Analysis}

The collected data was entered using Epidata version 3.1 and exported to SPSS version 25.0 for analysis. Descriptive and analytic statics were done. Descriptive statics was presented by texts, graphs and tables. Binary and multiple logistic regressions were applied to determine associated factors of preterm admission and immediate outcomes of preterm birth. Covariates and logistic regression assumptions were checked using goodness of fit by VIF test. Associations were described using odds ratio at $95 \% \mathrm{Cl}$ and statistical test was considered significant at a $P$ value of less than or equal to 0.05 .

\section{Result}

Among 228 neonatal medical charts reviewed, 212 neonatal medical charts with complete maternal and neonatal record were included in the study giving a response rate of $92.98 \%$.

\section{Analysis of maternal factors}

The mean age of the mothers of admitted neonate was 26.57 years old ( \pm 6.517 SD) within range of 18 to 44 years and 26 was the median age. More than half of the mothers $(54.2 \%)$ were below the mean age $(<26)$. One third 71 (33.5\%) of participants were from urban. Nearly half $108(50.9 \%)$ of mothers of admitted neonate were gravida 1 and most 199 (93.9\%) of mothers of admitted neonate were married (Table 1). 
Table 1

maternal socio-demographic factors of neonates admitted in NICU at

Debre Markos compressive specialised hospital, 2019

\begin{tabular}{|llll|}
\hline Variables & & Frequency $(\mathbf{N}=212)$ & Percent (\%) \\
\hline Age & $<26$ & 115 & 54.2 \\
\hline \multirow{2}{*}{ Residence } & Urban & 71 & 45.8 \\
\cline { 2 - 4 } & Rural & 141 & 33.5 \\
\hline Marital status & Single & 7 & 66.5 \\
\cline { 2 - 4 } & Married & 199 & 3.3 \\
\cline { 2 - 4 } & Divorced & 6 & 93.9 \\
\hline Numbers of gravidity & $<1$ & 108 & 2.8 \\
\cline { 2 - 4 } & $>2$ & 104 & 50.9 \\
\cline { 2 - 4 } & & & 49.1 \\
\hline
\end{tabular}

Regarding mode of delivery of neonates, spontaneous vaginal delivery accounts for $77.8 \%$ followed by Caesarean Sect. 20.8 (Fig. 1).

Regarding to mother's medical problem, about 86 (40.6\%) of the mothers had been diagnosed at least with one medical problem during the current pregnancy and 126(59.4\%) were not. From these $40(22.2 \%)$ had hypertension followed by premature rupture of membrane 23(10.8\%), Ante partum haemorrhage 11(5.2\%), anaemia 3(1.4\%), HIV 2(0.9\%) and others 7 (4\%) Fig. 2.

\section{Prevalence of preterm admissions and analysis of neonatal factors}

From the total neonatal admissions, 153 (72.2\%) were preterm birth admissions and 59 (27.8\%) were term birth admissions. The minimum and maximum gestational age of neonates were $26 \mathrm{wks}+6$ days and 40 $w k s+6$ days respectively with mean gestational age of $37.06( \pm 2.358$ SD).

The first minute APGAR score of the neonates was found to range 1 to 9 with mean of 5.98 and standard deviation of 1.436 where $129(60.8 \%)$ and $83(39.2 \%)$ were under category of low (0-6) and normal (>=7) APGAR Score respectively. The mean birth weight was 1679.95 grams $( \pm 396.174$ SD) while 700 gms was the minimum weight and the maximum to be 2600 grams. Majority of the neonates have low birth weight $141(66.5 \%)$, very low birth weight $61(28.8 \%)$ and $8(3.8 \%)$ have normal birth weight.

Regarding to medical problem of neonates, 201 (94.8\%) of the neonate were diagnosed at least to have one medical problem and the left 11 (5.2\%) had no medical problems on admission. Of these; 173 (81.6 \%) had hypothermia, 99 (46.7\%) had sepsis, 35(16.5\%) had hyaline membrane disease and 25(11.8) had respiratory distress (Fig. 3). 
Regarding to the outcome of neonates admitted in the NICU, 77 (36.3 \%) were died and 135 (63.7\%) neonates were discharged alive.

\section{Factors associated for preterm admissions}

In bivariate analysis neonates who have been borne from mothers who have been diagnosed at least with one medical illness during pregnancy was more likely preterm admissions than those who have not medical illness during pregnancy $(\mathrm{COR}=5.965,95 \% \mathrm{Cl}$ : $(2.911,12.223)$. Also, neonates who have been borne from mothers who have hypertension during pregnancy were more likely preterm admissions than those who have not hypertension during pregnancy (COR $=5.231,95 \% \mathrm{Cl}$ : $(1.986,13.782)$. neonates who have been borne from mothers who have diagnosed with premature rupture of membrane were more likely preterm admissions than those without premature rupture of membrane (COR $=5.231 \% \mathrm{Cl}$ : $(1.986,13.782)$.

In the multivariate analysis only neonates who have been borne from mothers who have hypertension during pregnancy remained significantly associated with preterm admissions. Neonates who have been borne from mothers who have hypertension during pregnancy were 4.464 times more likely preterm admissions than those neonates borne from mothers who have no hypertension during pregnancy $(\mathrm{AOR}=4.464,95 \% \mathrm{Cl}$ : $(1.375,14.498)$ (Table 2). 
Table 2

Analysis of factors associated with preterm admissions, Debre Markos, Ethiopia, 2019.

\begin{tabular}{|c|c|c|c|c|c|c|c|}
\hline \multirow[t]{2}{*}{ Variables } & & \multicolumn{2}{|c|}{$\begin{array}{l}\text { preterm birth } \\
\text { admission }\end{array}$} & \multirow[t]{2}{*}{$\begin{array}{l}\mathrm{P}- \\
\text { value }\end{array}$} & \multirow[t]{2}{*}{ COR (95\% C.I) } & \multirow[t]{2}{*}{$\begin{array}{l}\mathrm{p}- \\
\text { value }\end{array}$} & \multirow[t]{2}{*}{ AOR (95\% C.I) } \\
\hline & & Yes & No & & & & \\
\hline \multirow[t]{2}{*}{ Gravidity } & $<1$ & 78 & 30 & 0.119 & $\begin{array}{l}1.683(0.874- \\
3.239)\end{array}$ & 0.640 & $\begin{array}{l}0.796(0.305 \\
2.077)\end{array}$ \\
\hline & $>=2$ & 75 & 29 & & 1 & & 1 \\
\hline \multirow[t]{2}{*}{ Parity } & $<1$ & 78 & 30 & 0.119 & $\begin{array}{l}1.683(0.874- \\
3.239)\end{array}$ & 0.640 & $\begin{array}{l}0.796(0.305, \\
2.077)\end{array}$ \\
\hline & $>=2$ & 75 & 29 & & 1 & & 1 \\
\hline \multirow[t]{2}{*}{$\begin{array}{l}\text { Multiple } \\
\text { pregnancy }\end{array}$} & Yes & 43 & 15 & 0.427 & $\begin{array}{l}1.305(0.677- \\
2.518)\end{array}$ & 0.427 & $\begin{array}{l}1.305(0.677- \\
2.518)\end{array}$ \\
\hline & No & 110 & 44 & & 1 & & 1 \\
\hline $\begin{array}{l}\text { Hypertension } \\
\text { during }\end{array}$ & Yes & 31 & 9 & 0.001 & $\begin{array}{l}5.231(1.986- \\
13.782)\end{array}$ & 0.013 & $\begin{array}{l}4.464(1.375- \\
14.498)\end{array}$ \\
\hline Pregnancy & No & 122 & 50 & & 1 & & 1 \\
\hline \multirow[t]{2}{*}{ PROM } & Yes & 18 & 5 & 0.001 & $\begin{array}{l}5.231(1.986- \\
13.782)\end{array}$ & 0.706 & $\begin{array}{l}1.303(0.329 \\
5.170)\end{array}$ \\
\hline & No & 135 & 54 & & 1 & & 1 \\
\hline \multirow[t]{2}{*}{ Age of mothers } & $<26$ & 81 & 34 & 0.665 & $\begin{array}{l}0.867(0.455- \\
1.653)\end{array}$ & 0.665 & $\begin{array}{l}0.867(0.455- \\
1.653)\end{array}$ \\
\hline & $>=26$ & 72 & 25 & & 1 & & 1 \\
\hline \multirow[t]{2}{*}{ Maternal illness } & Yes & 45 & 41 & 0.001 & $\begin{array}{l}5.965(2.911- \\
12.223)\end{array}$ & 0.534 & $\begin{array}{l}0.857(0.328 \\
2.132)\end{array}$ \\
\hline & No & 108 & 18 & & 1 & & 1 \\
\hline
\end{tabular}

\section{Factors associated with immediate outcome of preterm birth}

In bivariate analysis, neonates with extremely low and very low birth weight neonates were more likely to be dead when compared to normal birth weight $(\mathrm{COR}=5.850,95 \% \mathrm{Cl}$ : $(3.086,11.089)$. Neonates with low APGAR score were more likely to die when compared to normal APGAR score (COR $=1.878,95 \% \mathrm{Cl}$ : $(1.037,3.404)$.

Neonates diagnosed with respiratory distress and hyaline membrane disease were more likely die when compared to neonates not diagnosed with respiratory distress and hyaline membrane disease $(\mathrm{COR}=4.108$, $95 \% \mathrm{Cl}:(1.677,10.06))$ and $(\mathrm{COR}=6.514,95 \% \mathrm{Cl}:(2.850,14.889))$ respectively. 
In multivariate analysis low APGAR score and extremely low and very low birth weight were significantly associated with neonatal death. Neonates who have low APGAR score at the 1 st and 5th minute were 3.113 times more likely to die than those neonates who have high APGAR score (AOR $=3.113,95 \% \mathrm{Cl}$ : $(0.019$, $0.669)$ ). Similarly, extremely low and very low birth weight neonates were 2.107 times more likely to die than normal birth weight neonates (AOR $=2.107,95 \% \mathrm{Cl}:(0.023,0.508)$ (Table 3$)$. 
Table 3

Analysis of factors associated with immediate death outcome of neonates, Debre Markos, Ethiopia, 2019.

\begin{tabular}{|c|c|c|c|c|c|c|c|}
\hline \multirow[t]{2}{*}{ Characteristics } & & \multicolumn{2}{|l|}{ Death } & \multirow{2}{*}{$\begin{array}{l}\mathrm{P} \text { - } \\
\text { value }\end{array}$} & \multirow{2}{*}{$\begin{array}{l}\text { COR }(95 \% \\
\text { C.I) }\end{array}$} & \multirow{2}{*}{$\begin{array}{l}\mathrm{P} \text { - } \\
\text { value }\end{array}$} & \multirow[t]{2}{*}{ AOR (95\% C.I) } \\
\hline & & Yes & No & & & & \\
\hline \multirow{2}{*}{$\begin{array}{l}\text { Hypertension } \\
\text { during } \\
\text { pregnancy }\end{array}$} & Yes & 12 & 28 & 0.130 & $\begin{array}{l}0.493(0.197- \\
3.043)\end{array}$ & 0.065 & $1.438(0.279,7.419)$ \\
\hline & No & 16 & 156 & & 1 & & 1 \\
\hline \multirow[t]{2}{*}{ PROM } & Yes & 10 & 13 & 0.195 & $\begin{array}{l}1.923(0.715- \\
5.171)\end{array}$ & 0.215 & $0.353(0.068,1.827)$ \\
\hline & No & 18 & 149 & & 1 & & 1 \\
\hline \multirow[t]{3}{*}{ Birth Weight } & $\begin{array}{l}\text { Very } \\
\text { low } \\
\text { birth } \\
\text { weight }\end{array}$ & 41 & 20 & 0.001 & $\begin{array}{l}5.850(3.086- \\
11.089)\end{array}$ & 0.005 & $2.107(0.023,0.508)$ \\
\hline & $\begin{array}{l}\text { Low } \\
\text { birth } \\
\text { weight }\end{array}$ & $34(24.2)$ & 107 & 0.002 & $\begin{array}{l}3.56(5.087- \\
8.67\end{array}$ & 0.003 & $1.986(1.56,6.798)$ \\
\hline & $\begin{array}{l}\text { Normal } \\
\text { birth } \\
\text { weight }\end{array}$ & 2 & 6 & & 1 & & 1 \\
\hline \multirow[t]{2}{*}{ APGAR score } & $0-6$ & $54(41.9)$ & 75(58.1) & 0.038 & $\begin{array}{l}1.878(1.037- \\
3.404)\end{array}$ & 0.016 & $3.113(0.019,0.669)$ \\
\hline & $>=7$ & $23(27.7)$ & $60(72.3)$ & & 1 & & 1 \\
\hline \multirow[t]{2}{*}{ Hypothermia } & Yes & $\begin{array}{l}70 \\
(40.5)\end{array}$ & $\begin{array}{l}103 \\
(59.5)\end{array}$ & 0.124 & $\begin{array}{l}2.039(0.823- \\
5.053)\end{array}$ & 0.558 & $0.561(0.081,3.882)$ \\
\hline & No & $7(25.0)$ & 21(75.0) & & & & \\
\hline \multirow[t]{2}{*}{$\begin{array}{l}\text { Respiratory } \\
\text { distress }\end{array}$} & Yes & $17(68.0)$ & $8(32.0)$ & 0.002 & $\begin{array}{l}4.108(1.677- \\
10.06)\end{array}$ & 0.595 & $0.600(0.091,3.944)$ \\
\hline & No & $60(34.1)$ & $\begin{array}{l}116 \\
(75.9)\end{array}$ & & & & \\
\hline \multirow{2}{*}{$\begin{array}{l}\text { Hyaline } \\
\text { membrane } \\
\text { disease }\end{array}$} & Yes & $26(74.3)$ & $9(25.7)$ & 0.001 & $\begin{array}{l}6.514(2.850- \\
14.889)\end{array}$ & 0.724 & $0.732(0.129,4.143)$ \\
\hline & No & $51(31.7)$ & $\begin{array}{l}115 \\
(68.3)\end{array}$ & & & & \\
\hline \multirow[t]{2}{*}{ Sepsis } & Yes & $38(38.4)$ & $61(61.6)$ & 0.983 & $\begin{array}{l}1.006(0.570- \\
1.777)\end{array}$ & & \\
\hline & No & $39(38.2)$ & $63(61.8)$ & & & & \\
\hline
\end{tabular}


In this study, we examined the relation between some maternal factors such as age, pregnancy induced hypertension and PROM with preterm admissions. This study showed the prevalence of preterm birth admissions was $27.8 \%$. This finding was similar to a study conducted by Kuppusamy et al in India (12) in which the prevalence of preterm admissions was $28.25 \%$. However, the finding of our study was higher than studies conducted by Kunle-Olowu, et al in southern Nigeria, Niger Tertiary Hospital which was 24\% (13)and studies conducted by Abebe $T$ in Addis Ababa which was16.15\% (14). This discrepancy might be due to differences in the incidence of preterm births in the various parts of the country as well as methodological and socio-economic differences across the studies.

In the present study there were more preterm males than females which is similar to the study by KunleOlowu, et al. in Nigeria and Abebe $\mathrm{T}$ in Addis Ababa who reported more preterm males. According to born too soon, preterm birth is more common in boys, with around $55 \%$ of all preterm births occurring in males worldwide (5).

In this study, $86(40.6 \%)$ of the mothers had been diagnosed at least with one medical problem during the current pregnancy which is similar with studies by Abebe T which was $40.6 \%$ (14).

In this study hypertension stands first 47 (22.2\%) and premature rupture of membrane $23(10.8 \%)$ is next cause to prematurity. But according to Kuppusamy and Vidhyadevi, in India the prevalent causes of prematurity were anaemia (28.42\%), preterm rupture of membrane (24.63\%) and pregnancy induced hypertension (18.23\%). In this study hypertension during pregnancy is significantly associated with preterm admissions. However, studies conducted by Kunle-Olowu, et al, Mahmoodi et al, in Tehran Iran and Margaret F Carter et al in Texas, the significant risk factors of preterm admission were PROM(11). This difference may probably due to difference in early identification and intervention of prenatal maternal problems across the country.

From those preterm neonates admitted to NICU 77 (36.3 \%) were died before discharge which is lesser when compared with the study done in Addis Ababa 45.3\% (14) and mean weight of the preterm in this study was 1679.95 grams $( \pm 396.174$ SD) which is nearly comparable with the mean weight $1669.4 \mathrm{gms}( \pm 508.688 \mathrm{SD})$ (14).

In this study respiratory distress and hyaline membrane disease has significant association with death outcome of preterm birth which is almost similar to Singh Uma, et al, India, Septicaemia, respiratory distress syndrome (RDS) and birth asphyxia were the important causes of neonatal morbidity(15). According to Kunle-Olowu, et al, the commonest medical conditions were respiratory problems in 95 (68.8\%) followed by jaundice in 94 (68.1\%) and sepsis in 54 (39.1\%) of the patients almost similar with this study (13).

In this study neonates with low APGAR score was significantly associated with death outcome. Similar findings are found in studies conducted by Kunle-Olowu, et al and Abebe T in Addis Ababa(13, 14). Also, in this study being extreme low and very low birth weight were significantly associated with death outcomes. This finding is supported with studies in Addis Ababa, Ethiopia and Legos Nigeria $(13,14)$. This might be due to extreme low and very low birth weight neonates are easily vulnerable to infections and physiological disturbances. 


\section{Conclusion}

Preterm admissions accounted for a significant percentage of neonatal admissions with significant death outcomes. Maternal medical problems like hypertension during pregnancy, premature rupture of membrane had significant association for preterm admissions. Being extreme low weight and very low weight baby, low APGAR score had significant association with death outcome of preterm neonates. Therefor, strategies should be designed to prevent preterm birth and their complications. Special attention should be given for pregnant mothers having medical problems especially hypertension. Furthermore, health institutions should have organised ANC follow up for regular screening of pregnant mothers for medical and obstetric complications.

\section{Declarations}

\section{Ethical approval and consent to participate}

Ethical clearance had been obtained from the institutional research ethics review committee of School of Medicine, Debre Markos University. Following this, permission letter was obtained from Debre Markos Referral hospital. Informed consent was not required, due to data was taken from chart review only but extracted data from medical record were kept confidentially

\section{Authors' contributions}

BA and AA performed the analysis and interpretations. BA wrote the first draft, TY and AA contributed to the design of the study and substantive revision of the final draft. All authors read and approved the final manuscript.

\section{Funding}

The author(s) received no financial support for the research, authorship, and/or publication of this article.

\section{Availability of data and materials}

All materials and data are available from the corresponding author without any restriction.

\section{Consent for publication}

Not applicable.

\section{Competing interests}

The authors declare that they have no competing interests.

\section{Acknowledgment}

We would like to express our great thanks to Debre-Markos referral hospital administrators. Next, we acknowledge our data collectors, supervisors, and friends that support us throughout our work. 


\section{References}

1. Blencowe $H$, Cousens $S$, Oestergaard MZ, Chou D, Moller AB, Narwal R, et al. National, regional, and worldwide estimates of preterm birth rates in the year 2010 with time trends since 1990 for selected countries: a systematic analysis and implications. Lancet (London, England). 2012;379(9832):2162-72.

2. The Europian Parliamentary Forum on Population and Development (EPF). Prematurity: The Hidden Burden in Reproductive Health, November 2014.

3. Osborn D, Cutter A, Ullah F. Universal Sustainable Development Goals: Understanding the transformational challenge for developed countries. Accessed on January 15, 2016.

4. Osborn D, Cutter A, Ullah F. Universal Sustainable Development Goals: Understanding the transformational challenge for developed countries. Accessed on January 15, 2016.

5. Blencowe H, Cousens S, Chou D, Oestergaard M, Say L, Moller A-B, et al. Born Too Soon: The global epidemiology of 15 million preterm births. Reproductive Health. 2013;10(1):S2.

6. Evans N, Hutchinson J, Simpson JM, Donoghue D, Darlow B, Henderson-Smart D. Prenatal predictors of mortality in very preterm infants cared for in the Australian and New Zealand Neonatal Network. Arch Dis Child Fetal Neonatal Ed. 2007;92(1):F34-F40.

7. Ethiopian Federal Ministry of Health. Health Sector Transformation Plan (2015/16-2019/20). 2015:1118.

8. Debelew GT, Afework MF, Yalew AW. Determinants and Causes of Neonatal Mortality in Jimma Zone, Southwest Ethiopia: A Multilevel Analysis of Prospective Follow up.

9. Kuppusamy and Vidhyadevi: Prevalence of Preterm Admissions and Risk Factors of Preterm Labor. International Journal of Scientific Study, December 2016,Vol 4.

10. Menon R. Preterm birth: a global burden on maternal and child health. Pathogens and G.

11. Zohreh M, Fatemeh H, Homa Avval S, Zahra G, Leila A. The Association between Maternal Factors and Preterm Birthand Premature Rapture of Membranes. Journal of Family and Reproductive Health. 1970;4(3).

12. Kunle-Olowu OE, Peterside O, Adeyemi OO. Prevalence and Outcome of Preterm Admissions at the Neonatal Unit of a Tertiary Health Centre in Southern Nigeria \%J Open Journal of Pediatrics. 2014;Vol.04No.01:9.

13. Deressa AT, Cherieb A, Negash BT (2018) Factors Associated with Induced Preterm Birth and Its Immediate Outcome in Addis Ababa Public Hospitals, Ethiopia. Neonat Pediatr Med 4: 170. DOI: 10.4172/2572-4983.1000170.

14. Sunita Sudhir P, Mishra S. A Prospective study of etiology and outcome of Preterm Labour in a Rural Medical College. Obg Rev: J obstet Gynecol 2016;2(4):60-64.doi: 10.17511/jobg.2016.i4.01.

15. Singh Uma et al. A Prospective Analysis of Etiology and Outcome of Preterm Labor. The Journal of Obstetrics and Gynecology, 2007, P 48.

\section{Figures}




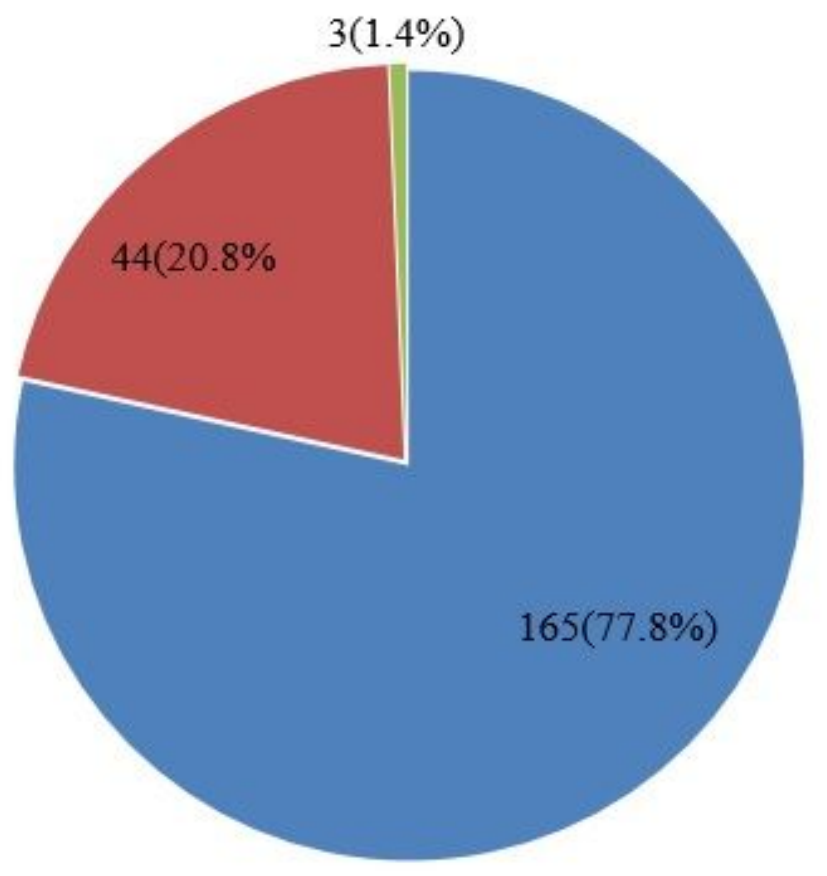

- Spontaneous vaginal delivery

- Caesarean section

- Assisted instrumental delivery

\section{Figure 1}

mode of delivery of neonates admitted in NICU at Debre Markos compressive specialised hospital, 2019. 


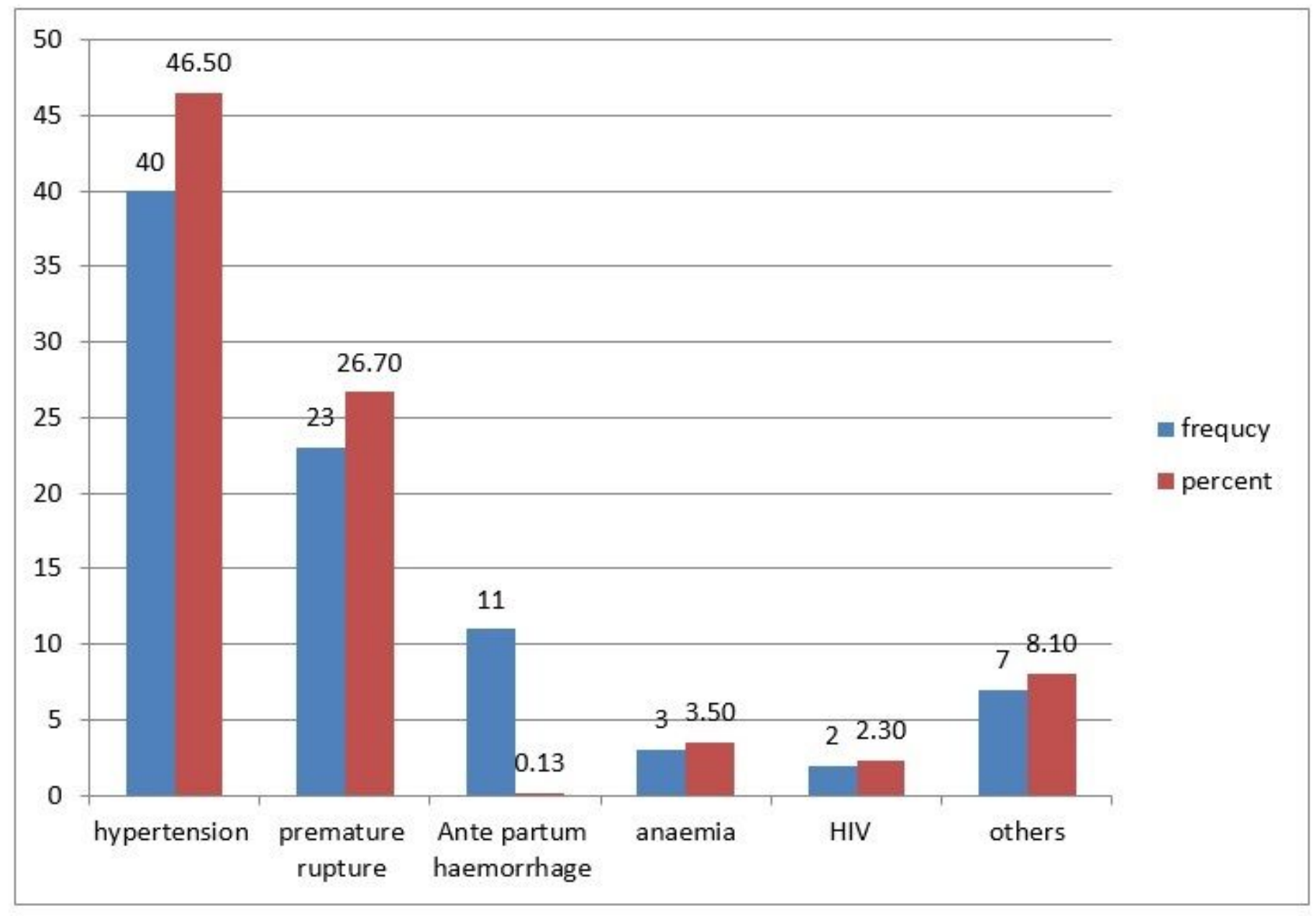

Figure 2

maternal medical problems of neonates admitted in Debre Markos hospital 


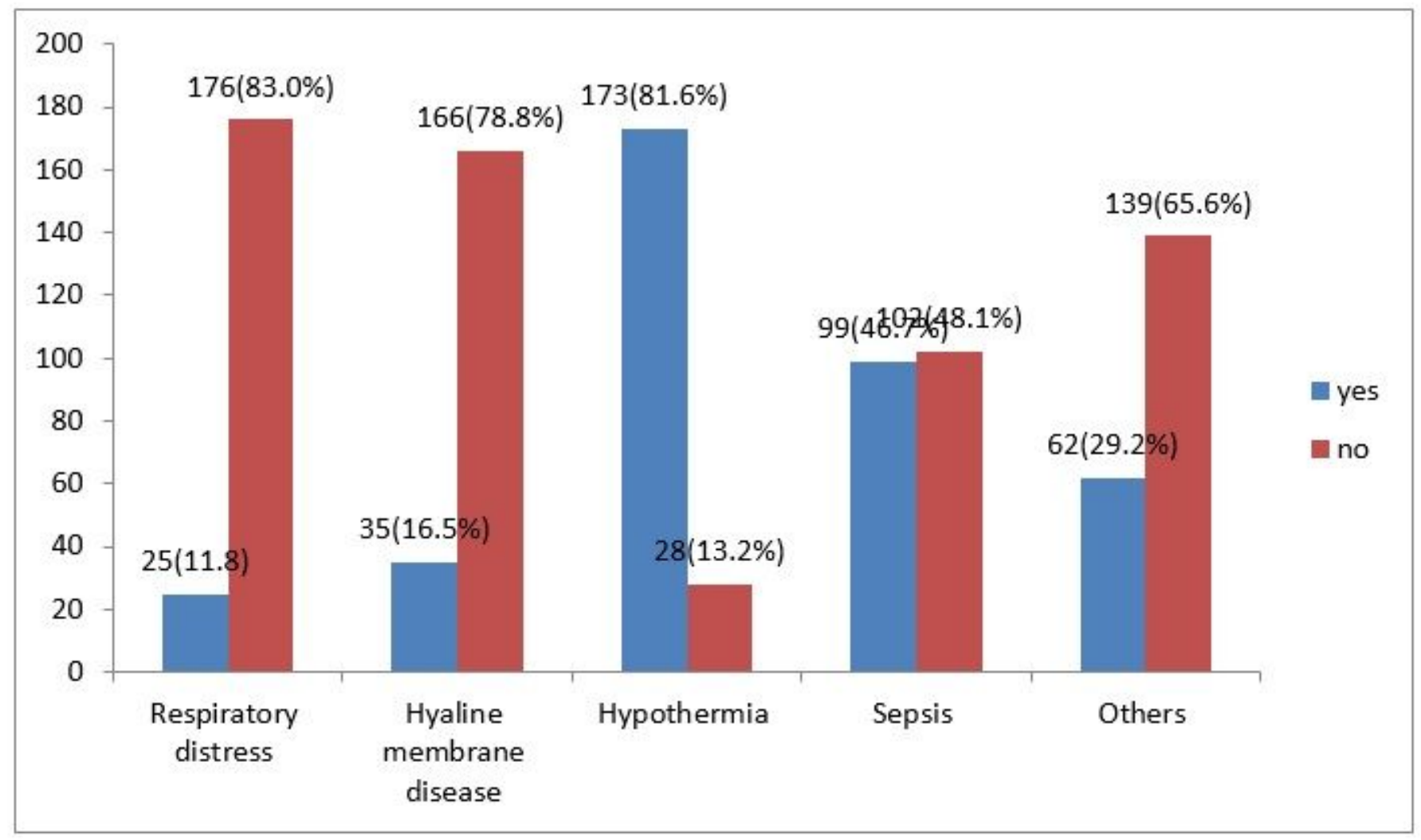

Figure 3

Common medical problems of admitted neonates in Debre Markos hospital, Ethiopia, 2019. 